\title{
ВРМБ в волокнах с W-профилем и периодическим изменением дисперсии вдоль волокна
}

\author{
Ю.А.Мажирина ${ }^{1}$, Л.А.Мельников ${ }^{1}$, А.И.Конюхов ${ }^{2}$, А.А.Сысолятин ${ }^{3, *}$, \\ К.С.Гочелашвили ${ }^{3}$, Д. Венкитеш ${ }^{4}$, С. Саркар ${ }^{4}$ \\ ${ }^{1}$ Саратовский государственный технический университет имени Ю.А. Гагарина \\ ${ }^{2}$ Саратовский государственный университет им. Н.Г. Чернышевского \\ ${ }^{3}$ Институт общей физики РАН им. А.М. Прохорова \\ ${ }^{4}$ Индийский институт технологии, г. Ченнай, Индия \\ "E-mail: alex@fo.gpi.ru
}

DOI: 10.31868/RFL2020.116-117

Вынужденное рассеяние Мандельштама-Бриллюэна (ВРМБ) препятствует достижению большой мощности стационарной генерации в одночастотных волоконных лазерах, поэтому разработка волокон с высоким порогом ВРМБ является важной задачей. Для параметрических усилителей на основе оптического волокна ВРМБ также является нежелательным эффектом.

Чтобы рассчитать порог ВРМБ, следует рассчитать спектр звуковых мод волокна, интегралы перекрытия звуковых и оптических мод[1-4]. Оптическое волокно с точки зрения акустических колебаний представляет собой слоистый стержень[3,4]. Будем рассматривать волокно с W -профилем показателя преломления[5,6]. При изменении показателей преломления областей трехслойной структуры изменяются акустические характеристики этих областей[9,10]. Существуют два подхода к оптимизации волокна. Один заключается в создании антиволновода для звуковых волн путем подбора материалов слоев[7,8], другой - в продольной модификации спектра ВРМБ усиления[9,10]. Оба подхода позволяют увеличить порог ВРМБ на 10-20 дБ. Возможно также применение модулированной накачки[11]. Для расчета акустических мод можно использовать приближение, при котором реальное распределение акустических параметров среды (скорости звука для поперечных и сдвиговых волн, параметров затухания и др.) заменяется на ступенчатые функции, которые, таким образом, моделируют соответствующую слоистую структуру волокна[12-13]. После чего можно использовать аналитические решения для слоев [12-14] или метод конечных элементов [15].

Был измерен профиль показателя преломления преформы из которой изготовлялось волокно с $\mathrm{W}$-профилем, а так же расчитан профиль основной моды такого волокна. Для расчета дисперсии записывалось поле основной оптической моды LP 01 в сердцевине, тренче и оболочке в обычном виде через функции Бесселя [16]. Сшивались поля и производные по радиусу на границах, и решалось характеристическое уравнение для поперечных волновых чисел. Это давало возможность рассчитать постоянную распространения для заданной длины волны, а также профиль моды. В результате вычислений в диапазона длин волн от 0.4 до 2.5 мкм, была получена аппроксимационная формула для постоянной распространения $\beta$ для волокна с показателями преломления сердцевины, тренча и оболочки, соответственно $\mathrm{n}_{\mathrm{c}}=1.453, \mathrm{n}_{\mathrm{t}}=1.435, \mathrm{n}_{\mathrm{o}}=1.444$ на длине волны 633 нм, и радиусами сердцевины и тренча $a=3$ мкм, $b=9$ мкм. При этих параметрах рассчитана дисперсия групповой скорости в зависимости от длины волны, показанная на Рис. 1 а.

Для расчета звуковых мод использовался подход, когда волокно представляется как многослойный стержень [12-13]. Результаты этих расчетов 
спектра усиления ВРМБ показаны на Рис.1б-в для того же волокна. При этом использовались выражения для скоростей звука, плотности и постоянных затухания из [5]. На Рис.1в видно, что в генерации ВРМБ участвуют несколько звуковых мод и, таким образом, генерируются несколько стоксовых волн. Для моделирования процесса их генерации использовался подход к решению уравнений распространения[19] с использованием метода Куранта - Изааксона Рис[20].

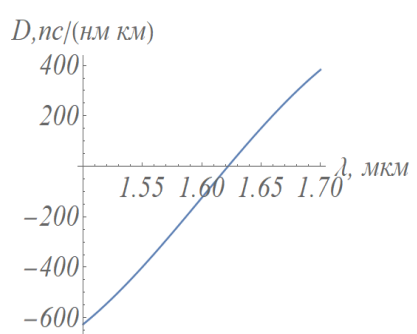

a)

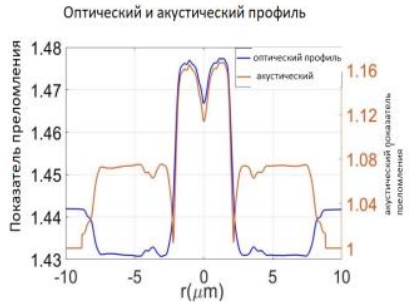

б)

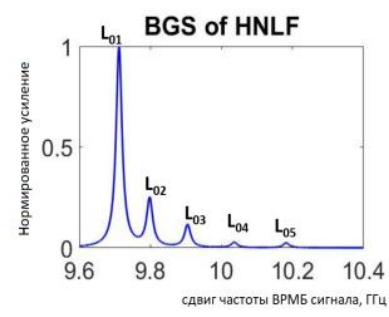

в)

Рис. 1. а) ДГС; б) Оптический и акустический профили; в) Спектр ВРМБ - усиления.

Работа поддержана грантом РФФИ № 19-52-45012

\section{Литература}

[1] Б. Я. Зельдович, А. Н. Пилипецкий, Квантовая электроника 13, 840-843 (1986)

[2] Б. Я. Зельдович, А. Н. Пилипецкий, Квантовая электроника 15, 1297-1304 (1988)

[3] C.K. Jen, Proc. of the IEEE Ultrasonic Symposium 1128-1133 (1985)

[4] R.N. Thurston, J. Acoust. Soc. Am. 64, 1-37 (1978)

[5] А.С. Беланов, Е.М. Дианов, Квантовая электроника 39, (2009)

[6] A.S. Belanov, E.M. Dianov et al, Quantum Electronics 39, 197-200 (2009)

[7] M.D. Mermelstein, Optics Express 17, 16225-16237 (2009)

[8] M. D. Mermelstein, M. J. Andrejco et al, Proc. of SPIE 7580, 75801G-1-75801G-13 (2010)

[9] A.S. Belanov, S.V. Tsvetkov, Quantum Electronics 40, 160-162 (2010)

[10] M.-J. Li, S. Li et al, OFC/NFOEC Technical Digest. Optical Fiber Comm. Conf. 6, 1-3 (2005)

[11] V.R. Supradeepa, Optics Express 21, 4677-4687 (2013)

[12] L. Dong, J. of Lightwave Tech. 28, 3162-3175 (2010)

[13] L. Dong, J. of Lightwave Tech. 28, 3156-3161 (2010)

[14] X. Qian, B. Han et al, Journal Instrum. Science \& Technology 41, 175-186 (2013)

[15] B. Ward, J. Spring, Optics Express 17, 15685-15699 (2009)

[16] M.Adams. Introduction to the theory of Optical Waveguides. John Wiley and Son, 1981.

[17] A.H. McCurdy, J. of Lightwave Tech. 23, 3509-3516 (2005)

[18] A. B. Ruffin, M.-J. Li. Optics Letters 30, 3123-3125 (2005)

[19] Мажирина Ю.А. и др. Прикладная нелинейная динамика, 22, 73(2014).

[20] Courant R., Isaacson E., Rees M. Commun. Pure Appl. Math., 5, 243 (1952). 